\title{
Ukrižena polarizacija i karakterizacija DSC Ljubo Gamulin fotoaparata testnom kartom boja
}

Hrvatski restauratorski zavod Odsjek za konzervatorsku dokumentaciju pokretne baštine ljgamulin@hrz.hr

Izvorni znanstveni rad/ Original scientific paper

Primljen / Received: 1. 5.2020 .

DOI: http://doi.org/10.17018/portal.2020.10

UDK: 778.68:[77.03:7.025
SAŽETAK: Tehnika fotografiranja ukriženom polarizacijom uobičajeno se koristi u digitalizaciji dvodimenzionalnih umjetničkih djela radi uklanjanja neželjene refleksije svjetlosti prisutne na slikama zaštićenima sjajnim površinskim lakom ili onih rađenih pastoznom tehnikom. Radi što manjeg odstupanja boja izvornika od dobivene master datoteke, uobičajeno prisutnog pri korištenju ukrižene polarizacije svjetlosti, predlaže se korištenje tehnika karakterizacije DSC fotoaparata metodom snimanja testne karte boja u skladu s normom ISO 17321-1:2012. Pokusna fotografiranja provedena su u kontroliranim uvjetima fotografskog studija. Ista umjetnina fotografirana je na tri načina: bez upotrebe polarizatora i s tvorničkom karakterizacijom, s ukriženom polarizacijom i tvorničkom karakterizacijom te s ukriženom polarizacijom i novom karakterizacijom. Osim vizualne usporedbe originala i master datoteka, uspoređene su kolorimetrijske razlike referentnih vrijednosti testne karte CCPP fotografirane uz umjetninu. Predložena metoda dala je najmanje pogreške kolorimetrijskih vrijednosti i zadovoljila kriterije normi ISO/TR 19263-1:2017 i ISO/TS 19264-1:2017 te fotografskih smjernica digitalizacije kulturne baštine.

KLJUČNE RIJEČI: fotografija, digitalizacija, ukrižena polarizacija, karakterizacija DSC fotoaparata, kolorimetrijske razlike
$\mathrm{O}$ vaj rad usmjeren je na primjenu ukrižene polarizacije $u$ dokumentacijskoj metodi fotografiranja umjetničkih djela, i to posebno za slike rađene pastoznom tehnikom pri geometriji svjetlosti od $30^{\circ} / 0^{\circ}$ do $45^{\circ} / 0^{\circ} .{ }^{1}$ Naime, u situacijama u kojima je potrebno istaknuti reljefnost pastoznih nanosa boja umjetničkih dvodimenzionalnih predmeta, uobičajeno se koristi tehnika dominantnog osvjetljenja s lijeve strane ili odozgo $\mathrm{u}$ odnosu na izvornik. ${ }^{2}$ Ista geometrija svjetlosti prisutna je u muzejskim standardima osvjetljenja. ${ }^{3}$ Osim nedostatka neujednačenosti snimane površine koja se regulira ujednačenjem svjetljivosti, takva geometrija svjetlosti na reljefnim pastoznim nanosima boje može uzrokovati neželjene refleksije. One se mogu ukloniti udaljavanjem izvora svjetlosti, oštrijim kutom svjetlosti ili upotrebom objektiva veće žarišne duljine, ali ako se fotografira u skučenom prostoru, to nije moguće. Zbog toga se fotografi koriste tehnikom ukrižene polarizacije, pri kojoj se zbog dikroizma (selektivne apsorpcije svjetlosti) potpuno uklanja odsjaj na slici. ${ }^{4}$ Glavni nedostatak 


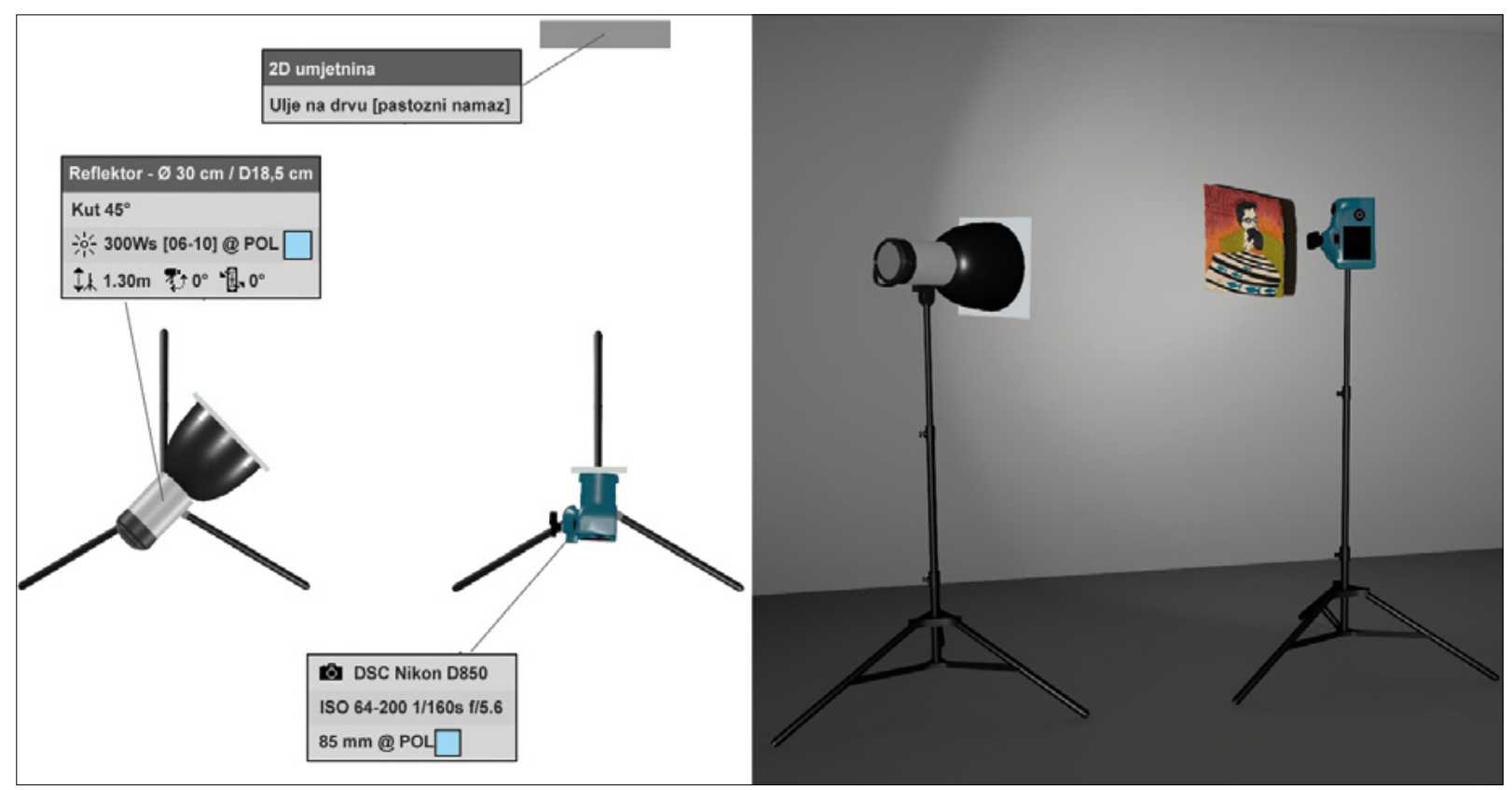

1. Shematski prikaz bljeskalice i fotoaparata u odnosu na snimani predmet. Izvor svjetlosti je filtriran linearnom polarizacijskom folijom. Svjetlost koja se odbija od predloška i dolazi do fotoaparata prolazi kroz cirkularni polarizator (izradio Lj. Gamulin, 2020.)

Diagram of the flash and camera relative to the subject. The light source was filtered with a linear polarizing foil. The light that bounces off the template and reaches the camera passes through a circular polarizer (Lj. Gamulin, 2020)

navedene tehnike je "gušenje” karaktera zlata i srebra te efekt „uljepšavanja”, odnosno pojačan kontrast i zasićenost boja u odnosu na izvornik. ${ }^{5}$ Cilj rada je pokušaj predstavljanja nove metode fotografiranja ukriženom polarizacijom, pri kojoj bi se u cijelosti uklonili efekti pojačanog kontrasta, zasićenosti boja i kolorimetrijskih razlika.

\section{Postupak fotografiranja}

Fotografiranje je obavljeno u studijskim uvjetima gdje je bilo moguće kontrolirati snagu, smjer i udaljenost svjetlosti u odnosu na snimani predmet te smanjiti neželjene refleksije. S obzirom na manju dimenziju snimanog umjetničkog djela $(20 \times 30 \mathrm{~cm})$, odabrana je studijska bljeskalica od $300 \mathrm{WS}$, klapne i standardni usmjerivač svjetlosti (reflektor) od $30 \mathrm{~cm}$. Geometrija položaja

Tablica 1. Validacija $L^{*}, a^{*}, b^{*}$ koordinata boja i ostvarene $\Delta \mathrm{E}_{00}$ vrijednosti (prema A-kategoriji norme ISO/TS 19264-1:2017) profila generiranog za ukriženu polarizaciju (izradio Lj. Gamulin, 2020.) Validation of $L^{*}, a^{*}, b^{*}$ colour coordinates and achieved $\Delta E_{00}$ values (according to category A of ISO/TS 19264-1:2017) of the profile generated for cross-polarisation (Lj. Gamulin, 2020)

\begin{tabular}{|l|r|r|r|}
\hline$\Delta \mathrm{E} \mathrm{2000}$ & $\begin{array}{r}\text { Mean } \\
\text { Deviation }\end{array}$ & Peak & $\begin{array}{r}\text { Standard } \\
\text { Deviation }\end{array}$ \\
\hline All & 0.48 & 2.53 & 0.71 \\
\hline Uniformity & 0.00 & 0.00 & 0.00 \\
\hline Reflection & 0.00 & 0.00 & 0.00 \\
\hline
\end{tabular}

rasvjetnog tijela i snimanog predmeta iznosila je $45^{\circ} / 0^{\circ}$. Fotoaparat Digital Still Camera (dalje DSC) korišten u testiranju bio je Nikon D850 s objektivom Tamron SP $85 \mathrm{~mm}$ F/1.8 Di VC USD postavljen na stativ. Fotografije su snimane i generirane programom Capture One. ${ }^{6}$ Za fotografiranje ukriženim polarizatorima korištena je linearna polarizacijska folija postavljena ispred izvora svjetlosti i cirkularni polarizacijski filtar postavljen na objektiv (sl. 1). Preciznim zakretanjem cirkularnog polarizacijskog filtra vizualno je određena i zadržana maksimalna moguća polarizacija svjetlosti. Da bi rezultati bili vjerodostojni, geometrija svjetlosti $45^{\circ} / 0^{\circ}$ nije mijenjana tijekom cijelog testa. Također je zadržan isti otvor zaslona (f 5,6). Budući da u programu za obradu fotografija nije mijenjanja ekspozicija, kompenzacija snage svjetlosti za različite uvjete fotografiranja regulirana je dijelom uz pomoć regulatora snage (dimera) na bljeskalici, a dijelom povećavanjem osjetljivosti fotografskog aparata. Fotografija bez polarizatora i s profilom proizvođača fotografskog aparata snimljena je pri osjetljivosti od 64 ISO, fotografija $\mathrm{s}$ ukriženim polarizatorima i s profilom proizvođača snimljena je pri osjetljivosti od 64 ISO i svjetlosti pojačanom na maksimum, a fotografija s ukriženim polarizatorima i s posebnim profilom pri osjetljivosti od 200 ISO i svjetlosti pojačanom za $1 / 3$. Razlog tim odstupanjima koji iznose čak 2-3 EV je dvojak. Prvi se odnosi na gubitak svjetlosti pri upotrebi polarizacijskog filtra koji se obično deklarira faktorom filtra x 2,5 (+1 EV), a može iznositi i x 3,5 (+1,6 EV). ${ }^{7}$ Drugi razlog je u postupku karakterizacije fotografskog aparata gdje je nužno odabrati linearnu 


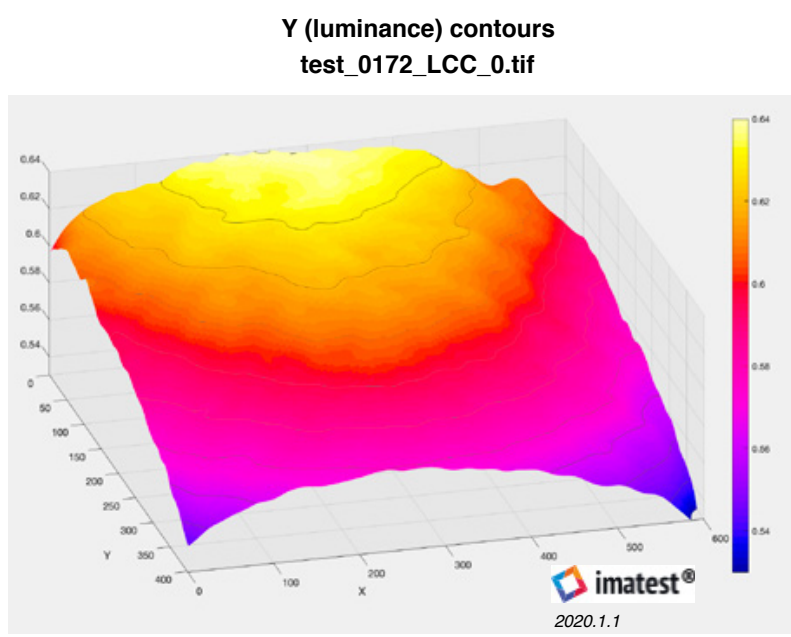

Max $=0.64$ (relative to 1 for pixel 255) [32x32 pxls areas]

Corners: worst $=0.525(82 \%) ;$ mean $=0.56(87.5 \%)$ Sides: $0.598(93.4 \%) \quad 0.572(89.3 \%)$; mean $=91.3 \%$

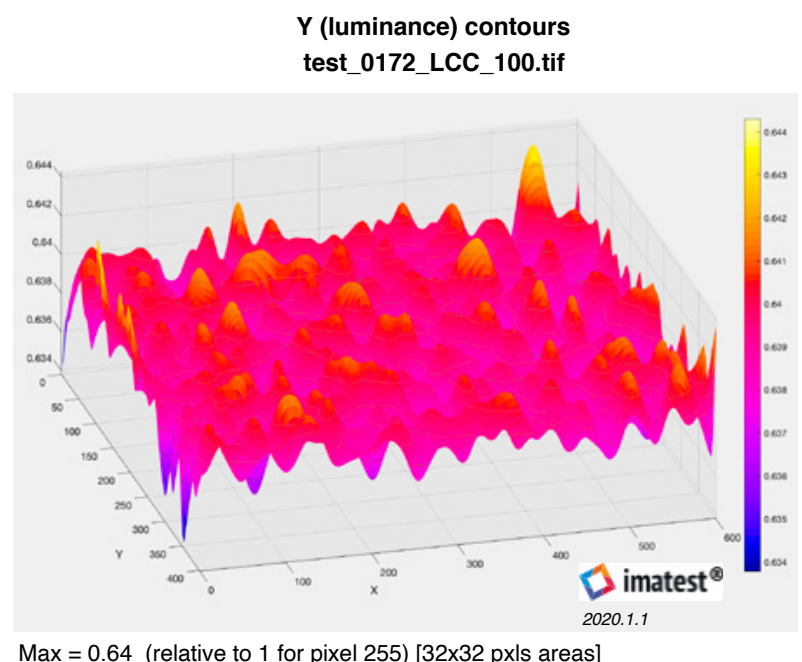

Max $=0.64$ (relative to 1 for pixel 255) [32x32 pxls areas]

Corners: worst $=0.635(98.6 \%)$; mean $=0.64(99.4 \%)$

2. Trodimenzionalni grafički prikaz i zabilježene vrijednosti raspodjele svjetljivosti Y (luminancije) na površini snimanog polja prije i nakon aplikacije LCC profila (izradio Lj. Gamulin, 2020.)

Three-dimensional display and recorded values of luminance distribution $Y$ on the surface of the photographed field before and after the implementation of the LCC profile (Lj. Gamulin, 2020)

krivulju koja isključuje sve korekcije digitalnog zapisa i rezultira sirovom nekarakteriziranom NEF datotekom. ${ }^{8}$ Zbog navedenih se odstupanja pri fotografiranju većih predmeta preporučuje upotreba jačih studijskih bljeskalica ili korištenje više bljeskalica.

\section{Ujednačenost raspodjele svjetljivosti - LCC profil}

Kako je za svjetlosni izvor odabrano samo jedno rasvjetno tijelo pod geometrijom $45^{\circ} / 0^{\circ}$, bilo je potrebno izjednačiti raspodjelu svjetljivosti (luminancije) unutar cijelog kadra. ${ }^{9}$ Za tu potrebu, u programu Capture One napravljen je LCC profil koji je primjenjivan tijekom cjelokupnog testiranja. ${ }^{10} \mathrm{U}$ kojoj je mjeri taj postupak nužan, potvrđuju izmjerene vrijednosti (sl. 2). Fotografija bez LCC profila imala je tolika vidna odstupanja u svjetljivosti da je bila neupotrebljiva za daljnji rad - zabilježen srednji postotak odstupanja na rubovima iznosio je 91,3\%, a na uglovima $87,5 \%$. U fotografiji s LCC profilom srednji postotak odstupanja na rubovima iznosio je 99,5\%, a na uglovima 99,4\%. Kako snimani predložak i testna karta nisu fotografirani u punom kadru, nego unutar približno dvije trećine snimane površine, realne vrijednosti odstupanja svjetljivosti bile su još manje, što je rezultiralo uravnoteženom svjetlošću. ${ }^{11}$

\section{Karakterizacija DSC fotoaparata}

Za karakterizaciju DSC fotoaparata i izradu posebnog ICC profila u uvjetima ukrižene polarizacije primijenjena je metoda fotografiranja testne karte ColorChecker Passport Photo proizvođača X-rite (dalje CCPP) generirane komercijalnim programom Basiccolor Input. Ona je zajedno s metodom spektralnog odaziva detaljno predstavljena $u$ normi ISO 17321-1:2012 revidiranoj 2017. godine. ${ }^{12}$ Nedostatak primijenjene metode $u$ odnosu na spektralnu je mogućnost utjecaja ljudske (fotografove) pogreške na konačni rezultat i ovisnost profila o korištenoj rasvjeti. ${ }^{13}$ U kontroliranim studijskim uvjetima gdje se položaj rasvjetnih tijela istih spektralnih karakteristika u odnosu na umjetninu može precizno odrediti, spomenuti se nedostaci mogu donekle umanjiti. Za fotografije in situ, gdje možemo očekivati različite svjetlosne uvjete, za svako snimanje potrebno je iznova raditi poseban profil, a element ljudske pogreške gotovo je nemoguće izbjeći. Drugi, ozbiljniji nedostatak skriva se u ograničenju testnih karata s obzirom na količinu i vrstu korištenih boja te odaziv boja s obzirom na mat, polusjajnu ili sjajnu površinu. Idealna testna karta trebala bi imati pigmente identične fotografiranoj umjetnini, što je u praksi teško ostvarivo. ${ }^{14}$ Zbog toga je potrebno odabrati testnu kartu koja najbolje može interpretirati boje upotrijebljene na reproduciranom predmetu. ${ }^{15}$ Ostvarene $\Delta \mathrm{E}_{00}$ vrijednosti generiranog profila zadovoljile su najstrožu A-kategoriju norme ISO/TS 19264-1:2017 te smjernice FADGI $* * * * *$ i Metamorfoze strict (tablica 1). ${ }^{16}$ Provjera profila također je pokazala da srednja odstupanja u odbljesku i svjetljivosti imaju vrijednost 0,00 .

\section{Eksperimentalni dio}

Sve su fotografije snimljene kao nekarakterizirane NEF datoteke. Točna ekspozicija i bijeli balans boje određen je na testnoj karti CCPP za svaku od testnih fotografija posebno, uz pomoć Adobe RGB i CIE L*a*b* referentnih vrijednosti. ${ }^{17}$ Iste vrijednosti korištene su u karakterizaciji DSC fotoaparata i konačnoj evaluaciji rezultata. Fotografije su eksportirane kao 16-bitni TIFF zapis s pridodanim 
a) test_0194.tif

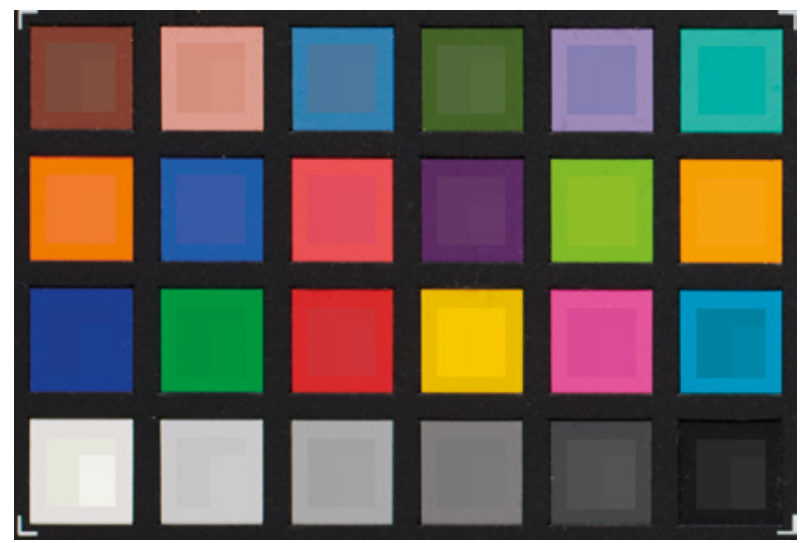

Adobe RGB (1998) / Exposure error $=0.27 \mathrm{f}$-stops Exp: 1/160 / Aper: 5,6 / ISO: 64

c) test_0197.tif

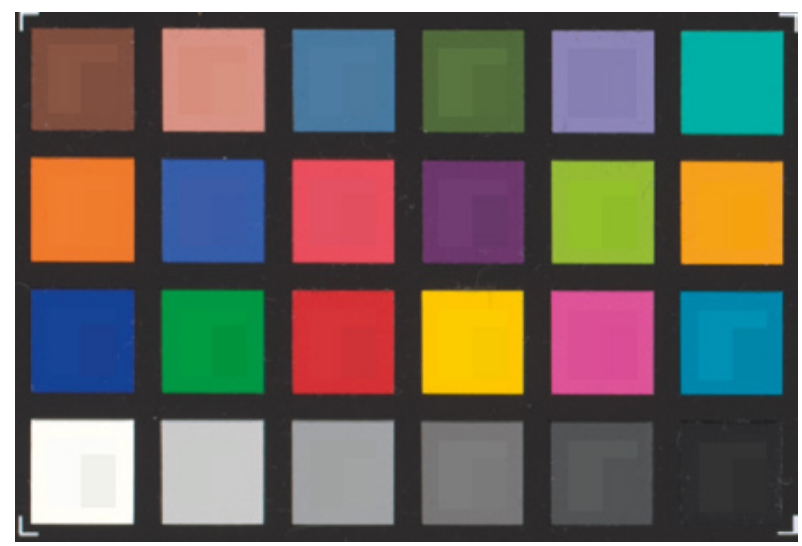

Adobe RGB (1998) / Exposure error = 0.02 f-stops Exp: 1/200 / Aper: 5,6 / ISO: 200 b) test_0195.tif

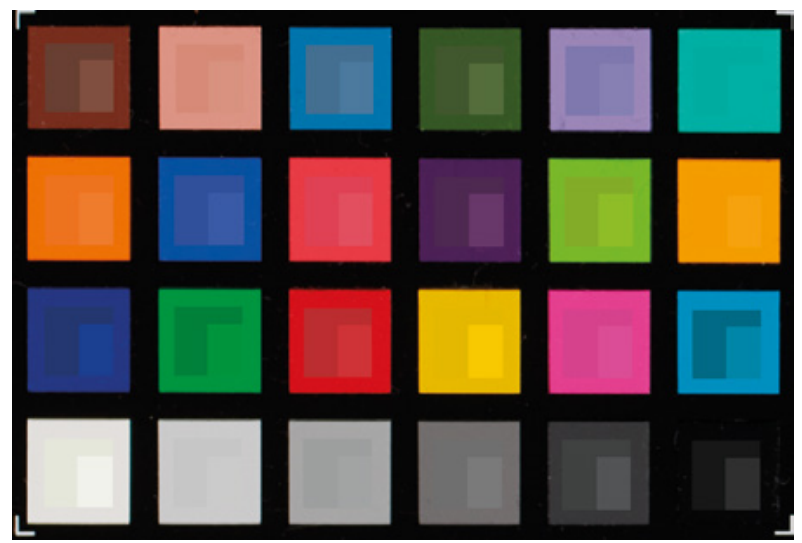

Adobe RGB (1998) / Exposure error $=0.38$ f-stops Exp: 1/160 / Aper: 5,6 / ISO: 64

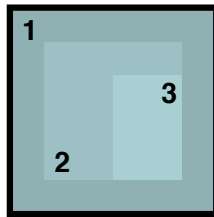

8 imatest $^{(1)}$ 2020.1.1

Vanjski kvadrat (polje 1) prikazuje fotografiran uzorak boje. Središnj kvadrat (polje 2) prikazuje referentnu vrijednost uzorka s korekcijom ukupne svjetljivosti (luminance) testne karte izražene kroz HSL geometriju boje. Najmanji kvadrat (polje 3) prikazuje idealnu vrijednost uzorka boje bez primjenjene korekcije svjetljivosti.

The outer region (zone 1 ) is the patch as photographed. The square in the center (zone 2) is the reference value of the patch, corrected for the luminanceof the photographed chart. The small rectangle (zone 3) to the right of the central square, is the ideal value of the patch, without luminance correction.

3. Prikazi ostvarenih, referentnih i idealnih boja testne karte: a) fotografija bez polarizatora i s tvorničkom karakterizacijom fotoaparata, b) fotografija s ukriženom polarizacijom i s tvorničkom karakterizacijom fotoaparata, c) fotografija s ukriženom polarizacijom i novom karakterizacijom (izradio Lj. Gamulin, 2020.)

Comparative display of achieved and ideal test-chart colours: a) photo without polarizer and with factory camera characterisation; b) photo with cross-polarisation and factory camera characterisation; c) photo with cross-polarisation and new characterisation (Lj. Gamulin, 2020)

a) test_0194

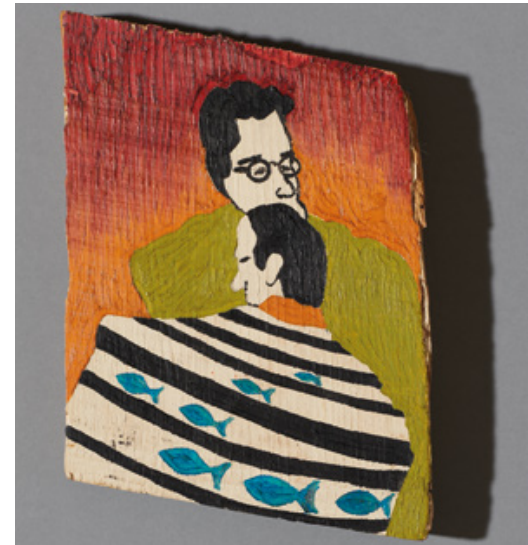

b) test_0195

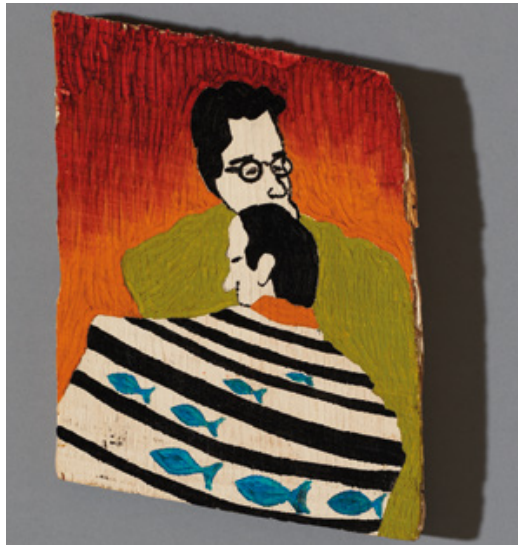

c) test_0197

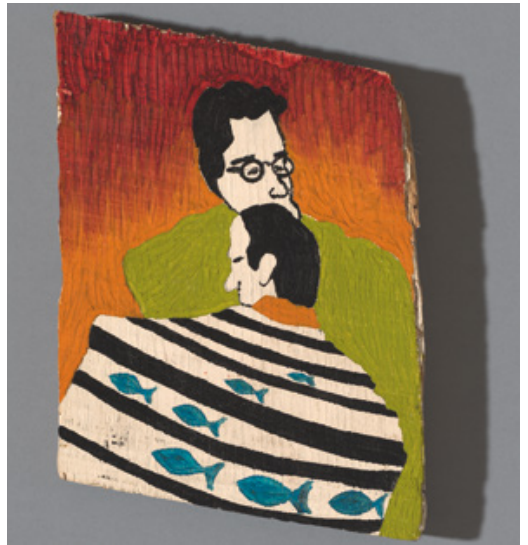

4. Usporedni prikaz fotografirane slike: a) fotografija bez polarizatora i s tvorničkom karakterizacijom fotoaparata, b) fotografija s ukriženom polarizacijom i s tvorničkom karakterizacijom fotoaparata, c) fotografija s ukriženom polarizacijom i novom karakterizacijom (snimio Lj. Gamulin, 2020.)

Comparative display of a photographed painting with thick impasto: a) photo without polarizer and with factory camera characterization; b) photo with cross-polarisation and factory camera characterisation; c) photo with cross-polarisation and new characterisation ( $\mathrm{Lj}$. Gamulin, 2020) 
a) test_0194.tif

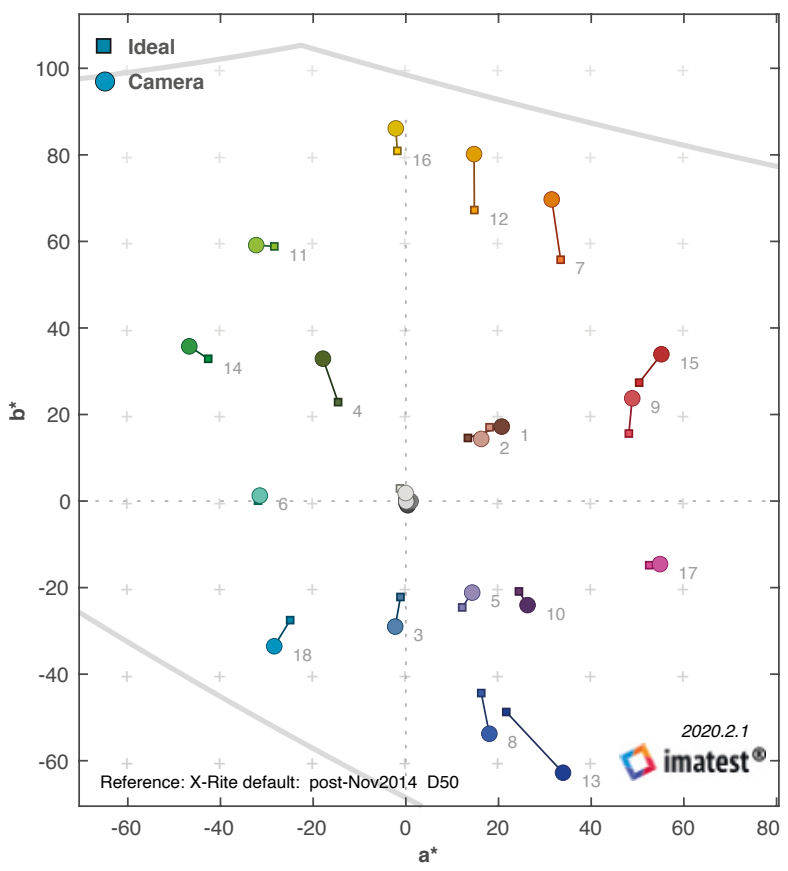

Mean camera chroma (saturation) $=112.8 \%$

Color errors: $\Delta \mathrm{C}_{00}:$ mean $=2.47 ; \max =5.66$

$\Delta \mathrm{C}_{00}$ chroma corr: mean $=2.04 ; \max =4.83$

$\Delta \mathrm{E}_{00}:$ mean $=3.75 ; \max =5.85$

$\mathrm{W}$ Bal (Zones 2-5) $\Delta \mathrm{C}_{00}=1.3$

Adobe RGB (1998) (D65)

\section{c) test 0197.tif}

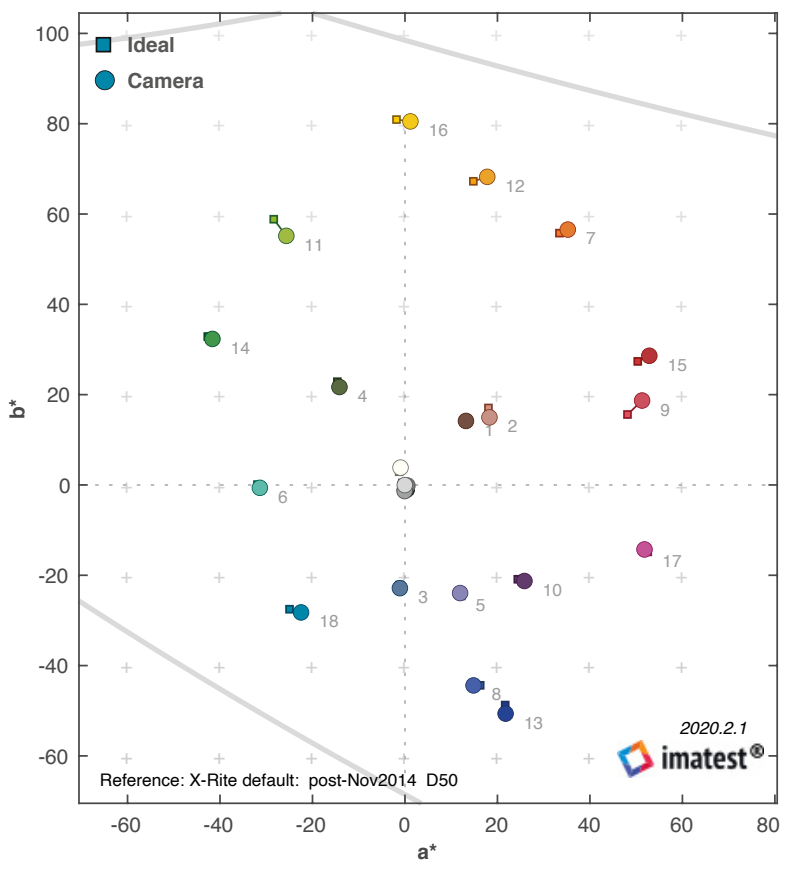

Mean camera chroma (saturation) $=100.4 \%$

Color errors: $\Delta C_{00}$ : mean $=0.908 ; \max =1.73$

$\Delta \mathrm{C}_{00}$ chroma corr: mean $=0.909 ; \max =1.73$

$\Delta \mathrm{E}_{00}:$ mean $=1.32 ; \max =2.69$

W Bal (Zones 2-5) $\Delta \mathrm{C}_{00}=1.1$

Adobe RGB (1998) (D65) b) test_0195.tif

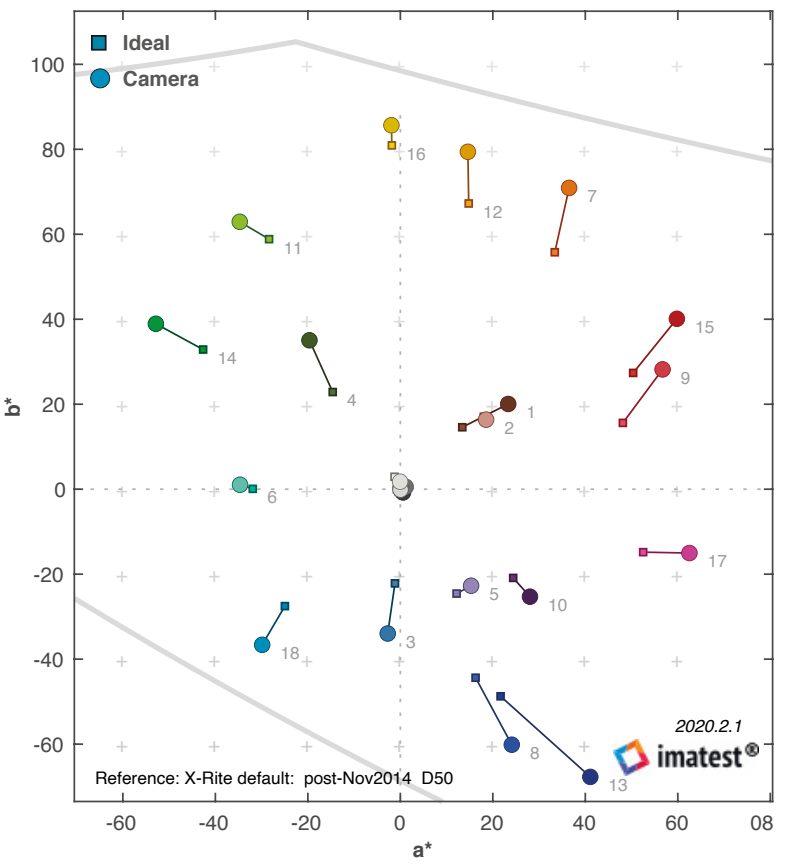

Mean camera chroma (saturation) $=122.3 \%$

Color errors: $\Delta \mathrm{C}_{00}$ : mean $=3.12 ; \max =6.52$

$\Delta \mathrm{C}_{00}$ chroma corr: mean $=2.16 ; \max =4.93$

$\Delta \mathrm{E}_{00}:$ mean $=5.19 ; \max =10.4$

$W$ Bal (Zones 2-5) $\Delta \mathrm{C}_{00}=1.4$

Adobe RGB (1998) (D65)
5. Grafički prikazi kolorimetrijskih razlika $\Delta \mathrm{E}_{00}$ i $\Delta \mathrm{C}_{00}$ na ravnini $a * b *$ CIELAB prostora boja: a) fotografija bez polarizatora i s tvorničkom karakterizacijom fotoaparata, b) fotografija s ukriženom polarizacijom is tvorničkom karakterizacijom fotoaparata, c) fotografija s ukriženom polarizacijom i novom karakterizacijom (izradio Lj. Gamulin, 2020.) Color differences $\triangle \mathrm{E}_{00}$ and $\triangle \mathrm{C}_{00}$ on the $\mathrm{a} * \mathrm{~b}$ * plane of CIELAB colour space: a) photo without polarizer and with factory camera characterisation; b) photo with cross-polarisation and factory camera characterisation; c) photo with cross-polarisation and new characterisation (Lj. Gamulin, 2020) 
profilom Adobe RGB.$^{18}$ Nikakve dodatne izmjene (korekcija ekspozicije, ton, oštrina, kontrast...) nisu rađene $u$ programu za obradu fotografija.

\section{Subjektivne vrijednosti - analiza promatranjem}

Testne fotografije promatrane su na profesionalnom kalibriranom monitoru. ${ }^{19}$ Bez obzira na moguću pogrešku subjektivnog promatrača, vizualne razlike između triju testnih fotografija toliko su izražene da nije bilo teško donijeti vrijednosni sud.

Fotografija a) s pridodanim tvorničkim profilom uz neželjeni efekt odsjaja svjetlosti na području grubog impasta pokazala je povećani kontrast i zasićenost svih boja. Crna boja prikazana je mnogo zasićenijom nego u stvarnosti. Taj pomak zasićenja boje $u$ odnosu na izvornik karakterističan je za sve DSC fotoaparate i odnosi se na želju proizvođača da snimljene fotografije izgledaju „bolje” od snimanog prizora. Primjetan je i pomak tona boje iz crvenog u narančasto, svijetlonarančasto u žuto i cijan u plavo. Na fotografiji b) s pridodanom tvorničkom karakterizacijom uz primjenu ukrižene polarizacijske svjetlosti, u cijelosti je anuliran efekt odsjaja. S druge strane, sve navedene karakteristike „uljepšavanja” slike $\mathrm{i}$ tonskih pomaka dodatno su pojačane. Fotografija c) $\mathrm{s}$ pridodanom posebnom karakterizacijom za ukriženu polarizacijsku svjetlost pokazala se kao mnogo vjernija izvorniku (sl. 3 i 4).

\section{Objektivne mjerne vrijednosti}

Kolorimetrijske razlike predstavljene su CIELAB prostorom boja u kojem se svaka boja može odrediti pripadajućim koordinatama. ${ }^{20}$ Izračun je zasnovan na tvorničkim referencama proizvođača za CCPP kolor karte proizvedene nakon studenog 2014. Mjerenja su izvedena komercijalnim programom Imatest Studio (sl. 5).

Uz pogrešku ekspozicije i ukupnu zasićenost boja, predstavljeni su mjerni podaci jednadžbi $\Delta \mathrm{C}_{00}$ i $\Delta \mathrm{E}_{00}$ pod CIE iluminatom D65. Razlika kromatičnosti boja na dvodimenzionalnoj $a * b *$ mreži koordinata (izostavljanjem vrijednosti svjetline $L^{*}$ ) izražena je jednadžbom $\Delta \mathrm{C}_{00}$. Ukupne kolorimetrijske razlike boja predstavljene su jednadžbom $\Delta \mathrm{E}_{00}$.

\section{Bilješke}

1. O geometriji položaja rasvjetnog tijela i snimanog predmeta vidi: ISO 14524:2009, 2009. Nasuprot navedenom, smjernice Američkoga društva za konzervaciju (JEFFREY WARDA, 2017.) definiraju obaveznu geometriju svjetlosti $25^{\circ}$. Ona je nekompatibilna sa smjernicama FADGI, Metamorfoze te sa svim ISO normama koje obrađuju digitalni fotografski zapis te zbog objektivnih razloga u ovom radu neće biti razmatrana.

\section{Zaključak}

Predstavljena je tehnika dokumentacijske fotografije dvodimenzionalnih umjetničkih predmeta slikanih pastoznim nanosima boje s ukriženim polarizatorima pri geometriji svjetlosti od $30^{\circ} / 0^{\circ}$ do $45^{\circ} / 0^{\circ}$ uz metodu karakterizacije CCPP testnom kartom. Njezina upotreba ostvariva je $u$ kontroliranim uvjetima studijske rasvjete, a učinkovitost ovisi o vještini fotografiranja testne karte, generiranja ispravne karakterizacije DSC fotoaparata i vrste umjetničkog predmeta koji se dokumentira. Za razliku od tehnike karakterizacije metodom spektralnog odaziva, predložena metoda ne iziskuje velika financijska ulaganja i može biti od interesa profesionalnim fotografima $u$ dokumentacijskim djelatnostima. Bez obzira na to što se korištena testna karta CCPP ne koristi u normama ISO/ TR 19263-1:2017 i ISO/TS 19264-1:2017 ni u smjernicama FADGI i Metamorfoze, ostvarene kolorimetrijske razlike zadovoljavaju najstrože kriterije spomenutih smjernica i A-kategoriju relevantne norme.

Zabilježeni podaci (sl. 5) upozoravaju na zabrinjavajuće velika kolorimetrijska odstupanja u rezultatima reprodukcijske fotografije koja se oslanja na tvorničke postavke DSC fotoaparata i ne primjenjuje ni jednu od spomenutih metoda karakterizacije. Podaci iz grafičkog prikaza a) s pridodanim tvorničkim profilom te prikaza b) s pridodanom tvorničkom karakterizacijom uz primjenu ukrižene polarizacijske svjetlosti ne zadovoljavaju normu ISO/TS 19264-1:2017 te niti jedan od ponuđenih kriterija smjernica FADGI i Metamorfose.

\section{Planovi za buduće istraživanje}

Iako se u normi ISO 17321-1:2012 uz testnu kartu CCPP za karakterizaciju DSC fotoaparata preporučuje jedino karta ColorChecker DG, na tržištu trenutno postoji desetak testnih karata različitih neovisnih proizvođača. Sljedeće istraživanje obuhvatit će testne karte koje imaju mnogo veći broj testnih boja i veći dinamički raspon sivog klina (preporučene vrijednosti u spomenutoj normi trebale bi se kretati od L* 12 do 92$).{ }^{21}$ Bit će korisno vidjeti u kojoj se mjeri karakterizacija testnim kartama može primijeniti na dvodimenzionalna umjetnička djela slikana različitim tehnikama i zaštićena različitim premaznim lakovima.

2. Općenito o tehnici dominantnog osvjetljenja u: DENIS VOKIĆ, 2019., 17-12.

3. ANSI/IES RP-30-17, 2017., 28, 43.

4. ANDY ROWLANDS, 2017., 3-34-3-39.

5. DENIS VOKIĆ, 2019., 37-39.

6. Odluka za korištenje aplikacije Capture One umjesto jednako učinkovitih programa kao što su Photoshop ili Lightroom donesena 
je ponajviše zbog praktičnijeg načina rada prilagođenog automatiziranom digitaliziranju umjetničkih djela.

7. RALPH JACOBSON, SIDNEY RAY, GEOFFREY G. ATTRIDGE, NORMAN AXFORD, 2000, 186-189.

8. DT DIGITIZATION GUIDE, 2017., 12.

9. Za detaljan način izrade LCC profila unutar programa Capture One vidi DT DIGITIZATION GUIDE, 2017., 21-23.

10. Zabilježene vrijednosti izračunate programom Imatest odnose se na kanal svjetljivosti definiran kao $Y=0,30 * R+$ $0,59 * \mathrm{C}+0,11 * \mathrm{~B}$.

11. Neujednačenost osvjetljenja snimanog polja u vrijednostima $\Delta L *$ prema normi ISO 17321-1:2012 iznosi $\leq 2(\leq A 3)$ i $\leq 5(\mathrm{~A} 2-\mathrm{A} 0)$ za kategoriju $A$ te $\leq 2(\leq \mathrm{A} 3) \mathrm{i} \leq 6(\mathrm{~A} 2-\mathrm{A} 0)$ za kategorije $B$ i $C$, prema smjernicama FADG $* * * *$ iznosi $<3$, a prema smjernicama Metamorfoze za sve kategorije iznosi 3 $(A 4-A 3)$ i $6(A 1-A 0)$.

12. ISO 17321-1:2012, rev. 2017.

13. KEITH BORRINO, FERNANDO VOLTOLINI DE AZAMBUJA, NITIN SAMPAT, J. A. STEPHEN VIGGIANO, 2017., 35.

\section{Norme i smjernice}

ANSI/IES RP-30-17, Recommended Practice for Museum Lighting, 2017.

HANS VAN DORMOLEN, Metamorfoze Preservation Imaging Guidelines, 2012.

Federal Agencies Digitization Initiative (FADGI) - Still Image Working Group, Technical Guidelines for Digitizing Cultural Heritage Materials: Creation of Raster Image Master Files, 2016.

ISO 12640-4:2011, Graphic technology - Prepress digital data exchange - Part 4: Wide gamut display-referred standard colour image data [Adobe RGB (1998)/SCID], rev. 2016.

ISO 12646:2015, Graphic technology — Displays for colour proofing - Characteristics, 2015.

\section{Literatura}

KEITH BORRINO, FERNANDO VOLTOLINI DE AZAMBUJA, NITIN SAMPAT, J. A. STEPHEN VIGGIANO, Sensitivity analysis applied to ISO recommended camera color calibration methods to determine how much of an advantage, if any, does spectral characterization of the camera offer over the chart-based approach, Electronic Imaging, 15 (2017.), 32-36

DT DIGITIZATION GUIDE, Digitization Workflows: Reflective, prepared by the Cultural Heritage teams at Digital Transitions and Phase One, 2017., URL = https://dtculturalheritage.com/store/digitization-workflows-re-flective-pdf-download/ (5. kolovoza 2018.) MARK D. FAIRCHILD, Color Appearance models, second edition, 2006. LJUBO GAMULIN, Primjena ISO normi, smjernica FADGI i Metamorfoze u digitalizaciji dvodimenzionalnih predmeta kulturne baštine, Portal, godišnjak Hrvatskog restauratorskog zavoda, 10 (2019.), 159-170
14. MAJA STRGAR KUREČIĆ, DARKO AGIĆ, LIDIJA MANDIĆ, 2007., 49-50; MAJA STRGAR KUREČIĆ, DARKO AGIĆ, LIDIJA MANDIĆ, 2011., 317-331.

15. S obzirom na to da je umjetnina fotografirana u ovom testu slikana uljanim bojama u pastoznim nanosima, a površina nije lakirana, za test je odabrana testna karta CCPP s matiranom površinom.

16. LJUBO GAMULIN, 2019., 159-170.

17. Za CIE L*a*b* vrijednosti CCPP karte proizvedene nakon 2014. godine vidi: https://xritephoto.com/ph_product_overview. aspx? ID $=2572 \&$ Action=Support\&Support $\mid \mathrm{D}=5159 \&$ catid $=158$ (17. kolovoza 2020.).

18. AdobeRGB kolor-profil preporučen je normom ISO 12640-4:2011

19. Monitor je kalibriran na iluminat $D 65$, odaziv tona $L *$, svjetlinom bijele $120 \mathrm{~cd} / \mathrm{m}^{2}$, sa srednjom kolorimetrijskom razlikom $\Delta \mathrm{E}_{00}=1,06$. Više o kalibraciji monitora ISO 12646:2015, 2015.

20. MARK D. FAIRCHILD, 2006., 80-82.

21. ISO 17321-1:2012, rev. 2017., anNex C.

ISO 14524:2009, Photography - Electronic still-picture cameras Methods for measuring opto-electronic conversion functions (OECFs), rev. 2015.

ISO 17321-1:2012, Graphic technology and photography - Colour characterisation of digital still cameras (DSCs) - Part 1: Stimuli, metrology and test procedures, rev. 2017.

ISO/TR 19263-1:2017, Photography - Archiving systems - Part 1: Best practices for digital image capture of cultural heritage material, 2017 ISO/TS 19264-1:2017, Photography - Archiving systems - Image quality analysis - Part 1: Reflective originals, 2017.

The AIC Guide to Digital Photography and Conservation Documentation, treće izdanje, 2017.

RALPH JACOBSON, SIDNEY RAY, GEOFFREY G ATTRIDGE, NORMAN AXFORD, Manual of photography, 9. izdanje, 2000. ANDY ROWLANDS, Physics of Digital Photography, 2017. MAJA STRGAR KUREČIĆ, DARKO AGIĆ, LIDIJA MANDIĆ, Color management implementation in digital photography, Journal of information and organizational sciences, 31/2 (2007.), 49-59 MAJA STRGAR KUREČIĆ, DARKO AGIĆ, LIDIJA MANDIĆ, Developing a custom colour target for artwork imaging, Imaging science journal, 59 (6) (2011.), 317-331

DENIS VOKIĆ, Fotodokumentiranje u konzerviranju i restauriranju baštine, radna verzija 23/2019. Skripta za kolegij Metodologija konzervatorsko-restauratorskog rada JEFFREY WARDA, (ur.), The AIC Guide to Digital Photography and Conservation Documentation, 2017. 


\section{Summary}

Ljubo Gamulin

\section{CROSS-POLARISATION AND CHARACTERISATION OF DIGITAL STILL CAMERA (DCS) WITH COLOUR TEST TARGETS}

This paper focuses on the use of cross-polarisation for documenting works of art with photographs, specifically for paintings made using the impasto technique at a geometry of light from $30^{\circ} / 0^{\circ}$ to $45^{\circ} / 0^{\circ}$. In situations where it is necessary to emphasize the ridges of impasto paint layers of artistic two-dimensional objects, the technique of dominant lighting on the left or above in relation to the original is usually used. In addition to the lack of unevenness of the photographed surface, which is regulated by brightness uniformity, the geometry of light on the ridges of impasto paint layers can cause unwanted reflections. These can be removed by moving the light source, using a sharper lighting angle, or using a lens with a longer focal length, but this cannot be done if photographing in a confined space. Therefore, photographers use the technique of cross-polarisation, in which, due to dichroism (selective absorption of light), the reflection in the painting is completely removed. The main disadvantage of this technique is the 'suffocation' of the character of gold and silver and the effect of 'beautification', i.e. enhanced contrast and colour saturation in relation to the original.
In order to minimize the deviation of original colours from the obtained master file, usually present when using cross-polarized light, the digital still camera (DSC) characterisation techniques for photographing colour test targets should be used. Test photographs were taken under controlled conditions in a photographic studio using a DSC and a studio flash. The same work of art was photographed in three ways: without the use of polarizers and with factory characterization, with cross-polarisation and factory characterization, and with cross-polarisation and new characterisation. In addition to a visual comparison of the originals and master files, the color differences of the reference values of the CCPP test chart photographed with the artwork were also compared. The proposed method gave the least number of errors regarding colorimetric values, and met the criteria of the standard ISO/ TS 19264-1:2017 and other photographic guidelines for digitization of cultural heritage.

KEYWORDS: photography, digitization, cross-polarisation, DSC characterisation, color difference 